\title{
Exploring the Potential Benefits of Using Social Media in Education
}

\author{
http://dx.doi.org/10.3991/ijep.v3i4.2836 \\ Rdouan Faizi, Abdellatif El Afia and Raddouane Chiheb \\ ENSIAS, Mohammed V Souissi University, Rabat, Morocco
}

\begin{abstract}
The objective of this work is to investigate the potential benefits of using social media in education. A thorough examination of a large set of these online tools has revealed that social media have many educational advantages. In fact, it has been found out that these webbased applications can improve communication among students and between teachers and students. Thanks to these technologies, both teachers and students can interact with each other in a matter of seconds. Social media can also be used to promote students' engagement. Students who often complain of being intimidated or bored in the classroom may feel comfortable to express their creativity and voice their opinion on a social network website. Another finding of this study is that social media applications foster collaboration as they allow students to work together to achieve a common goal. Given these educational benefits, we recommend that these online social tools should be used in learning environments.
\end{abstract}

Index Terms-Benefits, collaboration, communication, education, engagement, social media.

\section{INTRODUCTION}

In the last few years, the web has evolved from a medium for distributing a rudimentary and hyperlinked collection of read-only and static information resources to a set of social websites where people interact, share and constantly update huge amounts of decentralized information. In the past, the web was a one way information transfer tool as content was predominantly produced by experts, who published factual information and had the skills to create web pages. Users could only view websites but could not correct, change or add any content. Currently, the web has become an interactive and participatory "read-write" universal channel where users are allowed to be both producers and consumers of digital content in real time right through a web browser.

This new conception of the Web as a platform for computing and collaborative interaction has been supported by the development of so-called Web 2.0 technologies and standards. The result has been the fast proliferation of social media. The latter basically refers to a category of web-based tools and platforms that facilitates discussion, participation, and sharing of various forms of content (namely, text, video, audio and image) in a very convenient way.
The rapid growth of social media, mainly due to technological factors such as increased broadband availability, the improvement of software tools, and the development of more powerful computers and mobile devices, has been phenomenal. This type of media has actually become ubiquitous and part and parcel of the daily lives of millions of people around the globe and has a tremendous impact upon every facet of our personal and professional lives. Given that a large number of internet users are teachers and students, social media seem to have greatly influenced the way we teach and learn.

The objective of this paper is, therefore, to examine the potential benefits of social media in education. The rest of this paper is organized as follows. In Section Two we detail the different types of social media. Section Three presents the numerous opportunities that social media offer to both students and educators. Finally, Section Four gives a brief conclusion.

\section{SOCIAL MEDIA PLATFORMS}

Social media encompass a wide range of tools that integrate technology, social interaction and content creation. In the present work, analysis will be confined to the most popular social media types. These include social networks, blogs, micro-blogs, wikis, bookmarking, media sharing and RSS. In what follows, we provide a brief description of each of these social media types.

\section{Social Networks}

A social network is an online community that brings people with common interests, opinions, activities and experiences together by sharing their news, photos, videos, and events. A social network is essentially composed of a representation of each user (often a profile), his social links as well as a variety of additional services. These online communities also provide means for users to interact with each over the internet, such as email and instant messaging. Some of the most popular social networking sites are Facebook, LinkedIn, MySpace and Viadeo.

\section{Blogs}

Blogs are web-based logs or journals that enable users to post their thoughts, ideas, writing, and opinions for other people to view. Blogs are usually written by one 


\section{EXPLORING THE POTENTIAL BENEFITS OF USING SOCIAL MEdia IN EdUCATION}

person about a particular topic and are usually updated on a regular basis with entries displayed in reverse chronological order. They can either be self hosted or placed on a blogging network such as Blogger, WordPress or Tumblr.

\section{Micro-blogs}

Micro-blogs, as their name suggests, provide a similar function as traditional blogs, but with a much stronger focus on brevity. A micro-blogging website enables users to write short text messages and transmit them in realtime to their contacts. Micro-blogging can, therefore, be seen as a cross between blogging and social networking. The most famous micro-blogging service is Twitter.

\section{Wikis}

Wikis are websites that are developed collaboratively by a community of users. They allow any user to add, change, correct and post information for others to see. The largest and most popular wiki is Wikipedia, a usercontributed online encyclopedia currently hosting millions of articles in over more than 200 languages. Once published, articles on Wikipedia are considered to be "living content" as they are always subject to change and amendments by users.

\section{Social Bookmarking}

Social Bookmarking websites, also termed collaborative tagging systems, give people the opportunity to tag their favorite links and share the results with other users. Usually organized by topic, bookmarks can be saved privately, shared with certain people or groups, or available to the public. Delicious, Digg, Reddit, Stumbleupon, to name just a few, are good examples of websites offering bookmarking services.

\section{Media sharing}

Media sharing sites enable users to upload and share their multimedia content (photos, videos and audio) on the web. People can view the files uploaded by others, enrich them with tags, and share their thoughts through comments. Examples of such social media tools are YouTube, Flickr, iTunes and Shutterfly.

\section{$R S S$}

RSS (short for Really Simple Syndication) is a common component of social media websites. RSS allows websites and blogs to distribute their updated and dynamic content as feeds to different users. Hence, instead of visiting a given website regularly, the user can subscribe for free to as many feeds of information as desired and then access and mange those feeds all at once by making use of an RSS reader (e.g. Goggle Reader).

All these social media platforms can be grouped into three major categories. The first category includes social network sites like Facebook, Ning, MySpace and Twitter that serve as online communities via which users connect with friends or colleagues, and share ideas and resources. The second category consists of content sharing and organizing sites like Delicious, Digg, Flickr, YouTube, Dailymotion and RSS readers. The third category is composed of content creation and editing websites such as Blogger, Google Docs, Wikipedia and WordPress. Often times, however, the features and functions of a social media network can overlap, making a tool appropriate for more than one category.

\section{SOCIAL MEDIA: POTENTIAL EDUCATIONAL BENEFITS}

Despite being a recent addition to the Internet landscape, social media have witnessed an exponential growth. It is now infiltrating nearly every field, including the educational arena. These online social networks are increasingly being used for different reasons not only by students but by teachers as well [1], [2]. For this reason, a number of critics have started questioning the validity of social software in learning environments, stating that such tools may disengage students from learning traditional skills and literacies [3] or even destroy the traditional roles of teacher and learner [4].

However, after a thorough examination of a wide range of social media, it has been found out that these tools present many educational advantages for both students and instructors, hence, contribute in providing opportunities for further learning. These advantages are detailed below.

\section{A. Social Media as Communication Channels}

Studies have shown that the successful running of any learning experience depends on many things, one of which being effective communication between teachers and their students. If no proper communication between teacher and students is available, both teaching and learning will become difficult. For this reason, teachers need to continuously monitor students in order to be aware of any trouble the latter are having. Understanding the students' problems, fear, or confusion will help faculty better understand students' learning difficulties. The more connected the teachers are to their students, the more likely they are able to help students learn quickly and at a high level [5].

In this respect, a lot of educational institutions complain nowadays of their students' erratic behavior and poor scholastic performance. Educational experts believe that this is partially due to the absence of "connection" between teachers and students. Actually, experience has shown that if there is not enough communication between teacher and students, the feedback process remains thin or vague and optimal learning is not achieved. Proper communication between both parts can, therefore, remedy this problem.

Given that Internet users, the majority of which are students, use social networks mostly to keep in touch with friends, colleagues, peers and family, it is important to explore the possible benefits that such networking tools can offer to modern education. These web-based 
platforms could actually be used to enhance communication between the different actors of the educational system, namely, student, faculty and staff.

Facebook, MySpace and Twitter, for instance, can serve as backchannels for communication among students and between teachers and students within or between classes. Instructors can answer students' questions via a Facebook page or Twitter feed, post homework assignments and lesson plans, extend in-class discussions, send messages and updates, schedule or announce forthcoming events, and inform learners about special lectures, panel discussions or guest speakers. This teacher-student interaction will certainly contribute in understanding various learning related difficulties and solving them in less time.

Social media can improve communication not only between students and teacher but also among students. The latter can use social networks to talk to each other about upcoming assignments or tests. They can get details from their classmates about materials that will be covered on a test or the requirements for one or more assignments. If students are having trouble with a certain topic, they can go to classmates on a social networking website to get assistance and catch up online. Similarly, as blogs and wikis involve the contribution of multiple users, these collaborative tools can successfully enhance interactivity among students [6].

\section{B. Social Media as Engagement Tools}

Social media tools are also effective ways to increase students' engagement. As the social features of social media resources have attracted the attention of millions of people around the globe, these same features are also capable of drawing the attention of students to the learning opportunities provided by their academic institutions [7]. A student who hardly ever participates in class may get actively engaged in co-constructing his learning experience with his teachers, collaborating with his fellow colleagues, and may feel more comfortable to express himself and to share his resources and ideas on Facebook, Twitter, or YouTube [8].

Using tools such as Google Apps for Education or Ning would enable students to have access to valuable learning resources regardless of time and place. Within the traditional classroom, providing students with additional learning materials can be very expensive and logistically complicated. However, using social media can enhance the learning experience. In fact, inviting students to participate in the different learning activities available on social learning platforms would serve to support academic engagement by extending the amount of time a student spends in doing his homework or related school projects [9].

Moreover, given that many students often complain of getting bored or intimidated at school, the dynamic and participatory nature of many social media resources could be used to engage or re-engage bored or shy students.
Collaborative and participatory tools like Wikis, blogs, Google Docs can encourage students to become active participants or even co-producers rather than passive consumers of content [8].

Following a number of studies, the major factor that students frequently cite as the cause of their boredom at school is that the materials are not always interesting or relevant. Some other bored students, however, indicate that the source of their boredom is mainly due to a lack of interaction with their teachers. In fact, experience has shown that instructional methods that involve working and learning with peers are the most highly rated of all the instructional methods that teachers use [10]. To counter classroom boredom and enhance behavioral engagement, social media tools could be used to design learning activities that are both social and interactive (e.g. discussion, debate, group projects, etc.). This would enable students to learn from each other and interact with other people beyond the school walls.

Besides promoting student-student interactions, social media can also be used to enhance and increase the number of interactions students may have with their teachers by overcoming the barriers of time and location [9]. Consequently, students would have enough opportunities to ask questions, make comments, as well as get feedback. As such, they will have more chances to develop supportive relationships with their instructors.

\section{Social Media as Collaborative Platforms}

Another vital benefit of social media is that they foster collaboration. Collaboration means working together jointly, intellectually, and socially to achieve common goals. Within an online learning community, collaboration refers to any instructional method in which students work together in groups towards a common goal [11]. As such, collaborative learning can be viewed as encompassing all group-based instructional methods, including cooperative learning.

Following Ingram and Hathorn [12], true collaboration consists of three critical elements: participation, interaction, and synthesis. This means that collaboration in educational settings requires that students move beyond merely dividing up assignments. True collaboration is not only asking students to independently produce separate parts of a project; it actually means working together on shared tasks. In this respect, Prince [13] claimed that the core element of collaborative learning is that emphasis is on student interactions rather than on learning as a solitary activity.

Given the importance of collaboration in the learning process, a great number of social media tools serve as platforms for learners to gather and share information and resources from both internal and external collaboration networks. Online learners, who could be students, educators, or any other individual in the community, can thus generate their own learning content and take 


\section{EXPLORING THE Potential BENEFITS OF Using Social MEdia IN EdUCATION}

advantage of collective knowledge. In this sense, social media are an effective means to create channels of collaboration between students and teachers and amongst students.

As opposed to classical instructional models that tend to concentrate on individual processes of learning, social media collaboration platforms enable a shift in individual thinking about the energy and intelligence that can be produced collaboratively. The power of collaborative content tools is in their ability to offer a single destination where people bring their ideas together, examine them with their peers, and publish them in a way that can be revised and revisited. Research has demonstrated that students learn better when they are actively involved in the process, and that students working in groups tend to learn more and retain it longer than in other instructional formats [14], [15]. While simply acquiring information can be carried out alone, students' problem-solving skills are often better enhanced in a collaborative environment. Social media actually allow students to work together on projects beyond an individual's capability.

This category of collaborative social media tools includes wikis, which are websites or open forums that allow multiple users to exchange and work on the same content. According to Parker and Chao [16], wikis are ideally suited to collaborative writing due to their open editing and review structure. Authors such as Thorne and Payne [17] noted that wikis are unique because they blur the line between the author and the audience by allowing multiple users to edit and add to the wiki. Wikis often annotate additions and deletions with the author's name and the time and date the change is made, thus, making it possible for teachers to verify the participation of various group members.

\section{CONCLUSION}

The objective of this paper was to explore the potential advantages of social media in education. A thorough examination has actually revealed that these online social tools have many educational benefits. Indeed, it has been shown that social media enhance communication and interaction among students and between teachers and students. Thanks to these platforms, instructors and students are now able to communicate with each other within or between classes. It has also been found out that social media are an effective way to promote students' engagement as it enables shy, intimidated or bored students to share ideas and to express their opinions in a more comfortable way. An additional educational advantage of social media applications is that they foster collaboration given that they offer teachers and students a single destination where they can bring their ideas together, examine them with their colleagues and publish in a way that be edited. Taking into account all these benefits, we strongly believe that social media could be used as valuable educational tools capable of enriching the learning experience. Therefore, we recommend that educators use these online social communities whether they are working in fully online, blended, or face-to-face learning contexts.

\section{REFERENCES}

[1] Mazer, J. P, Murphy, R. E, \& Simonds, C. J. (2007). I'll see you on "Facebook": The effects of computer-mediated teacher selfdisclosure on student motivation, affective learning, and classroom climate. Communication Education, 56(1). http://dx.doi.org/10.1080/03634520601009710

[2] Mazer, Joseph P., Murphy, Richard E., \& Simonds, Cheri J. (2009). "The effects of teacher self-disclosure via Facebook on teacher credibility". Learning, Media \& Technology, 34(2), 175183. http://dx.doi.org/10.1080/17439880902923655

[3] Brabazon, T. (2007). The university of Google. Aldershot: Ashgate

[4] Sickler, E. (2007). "Students comment on Facebook". University Business. March. Retrieved from http://www.universitybusiness.com/ viewarticle.aspx? articleid $=724$

[5] Jones, V. F. \& Jones, L. (1981). Responsible Classroom Discipline. Boston: Allyn and Bacon.

[6] Lin, H. T. \& Yuan, S. M. (2006). "Taking blog as a platform of learning reflective journal". ICWL, 2006, 38-47

[7] Rutherford, C. (2012). "Using Social Media to Support Student Engagement". Retrieved from http://www.drcamillerutherford.com/2012/02 /using-social-mediato-support-student.html

[8] McLoughlin, C. \& Lee, M. J. W. (2007). "Social software and participatory learning: Extending pedagogical choices with technology affordances in the Web 2.0 era". In R. Atkinson \& C. McBeath (Eds.), ICT: Providing choices for learners and learning. Proceedings of the 24th ASCILITE Conference, 664675. Singapore, December 2-5.

[9] Rutherford, C. (2010). "Using Online Social Media to Support Preservice Student Engagement". Journal of online learning and teaching, Vol. 6(4).

[10] Yazzie-Mint, E. (2010). Charting the Path from Engagement to Achievement: A Report on the 2009 High School Survey of Student Engagement. Indiana University Center for Evaluation and Education Policy (CEEP)

[11] Mattessich, P., Murray-Close, M., \& Monsey, B. (2001). Collaboration - what makes it work, 2nd ed., Amherst H. Wilder Foundation: Saint Paul, Minnesota.

[12] Ingram, A. L. \& Hathorn, L. G. (2004). "Methods for analyzing collaboration in online communications". In S. T. Roberts (Ed.) Online Collaborative Learning: Theory and Practice (pp. 215 - 240). Hershey, PA: Information Science

[13] Prince, M. (2004). "Does active learning work? A review of the research". Journal of Engineering Education 93, 223-231. http://dx.doi.org/10.1002/j.2168-9830.2004.tb00809.x

[14] Dawley, L. (2007). The tools for successful online teaching. Hershey, PA: Information Science Pub. http://dx.doi.org/10.4018/978-1-59140-956-4

[15] Agosto D. E., Copeland A. J. and Zach L. (2012). "Using Social Technologies to Foster Collaboration and Community Building in Face-To-Face Classrooms". Retrieved from https://slis.iu.edu/accreditation/ Appendix2.4.php

[16] Parker, K. R., \& Chao, J. T. (2007). "Wiki as a teaching tool. Interdisciplinary Journal of Knowledge and Learning Objects", 3, 57-72. Journal of online learning and teaching, Vol. 6(4).

[17] Thorne, S. L. \& Payne, J. S. (2005). "Evolutionary trajectories, Internet-mediated expression, and language education". CALICO journal, 22(3), 371.

\section{AUTHORS}

Rdouan Faizi, Abdellatif El Afia and Raddouane Chiheb are with ENSIAS, Mohammed V Souissi University, Rabat, Morocco (e-mail: faizi@ensias.ma, elafia@ensias.ma, chiheb@ensias.ma).

Submitted, 27 May 2013. Published as re-submitted by the authors 09 July 2013. 